\title{
COMMENT
}

\section{The one new journal we might actually need}

\author{
Gregory A Petsko*
}

Just so there's no mistake when it comes to your Christmas shopping, these are some of the things I DON'T want this holiday season:

- A Republican President

- A Republican majority in Congress

- Longer seasons for any professional sport

- Anyone with a degree in economics giving any advice to any government

- Anyone in any government listening to anything any economist says

- A flat NIH budget

- Budget cuts with no tax increases

- Another winter like the last one

- A tea party that does anything except actually serve tea

- A sequel to any movie that was even halfway good

- Political candidates who are so stupid that they should be watered twice a week

- Religion, of any kind, sticking its nose into my government

- Analysts and pundits making any more predictions about anything

- More 'big science' projects without a lot more 'little science' being funded first

Should anyone attempt to put one of these in my stocking, no matter how prettily it's wrapped, it will be returned with a nasty note. Don't say you haven't been warned.

But there is one thing that I thought I was going to put on this list that, instead, I find I actually do want for Christmas: another scientific journal.

Before I explain why I've changed my mind about the desirability of yet another scientific periodical, it's worth taking a look at the current state of the journal world we live in at the moment. Besides the obvious fact that there are an awful lot of them, what best characterizes the journals of 2012 is their belonging to one of two broad classes. Trade journals, which is by far the largest class, are journals that specialize in a field, or sub-field. Papers in these journals tend to be written for the cognoscenti, and reflect that by the use of some jargon, and an

*Correspondence: petsko@brandeis.edu

Rosenstiel Basic Medical Sciences Research Center, Brandeis University, Waltham, MA 02454-9110, USA assumed background on the part of the reader. The vast majority of all scientific papers, including many of extremely high impact, are published in these specialty journals, and until relatively recently, most scientists aspired to publish nearly all of their papers in the best of them. The second class, which is really the subject of this column, comprises the general journals, sometimes called the boutique journals, and there are very few of these. The class is dominated by three journals (although two of them are actually franchises, and have spawned a set of more specialized offspring). They are the cause of much of the problem with the way scientific publication works - or doesn't - today, but since not all of the trouble is their fault, I shall not refer to them by name. Let us call them, to disguise their identities, Nurture, Spineless, and $\mathrm{Hell}$, and refer to them hereafter as The Big Three (TBT). TBT and other general journals publish papers in many different fields, and tend to require that papers in them be written for readers with a relatively wide range of backgrounds.

TBT reject a very high percentage of the manuscripts that are submitted to them, with the majority of these rejections coming without peer review. Instead, a staff of editors, who are not practicing scientists but typically have postdoctoral research training, typically carry out this initial triage, although they may seek the advice of one or more members of a board of practicing scientists who are on call. Because of the high rejection rate, it is assumed that papers published in TBT must be of exceptional quality and impact. And that assumption, which is not always valid, is the cause of many difficulties.

For one thing, it seems to have convinced the scientists who are chosen to review papers for TBT that they can only accept complete stories. Since very few manuscripts would meet that description, on the rare occasions that said reviewers do not reject the papers outright, they feel obliged to manage (some would say, micromanage) the science in them by suggesting a host of additional experiments that would be needed to make the story complete enough for their taste. In many cases these experiments outnumber the original ones, and take almost as much time to carry out. And yet, in my experience, the quality of the reviewing in TBT is often inferior to that of the best trade journals (if you doubt this, count the number of seriously wrong papers 
published in the general journals; you will find it out of proportion to the relatively few papers that appear there at all). Which means that it is far from certain that the reviewers are right in their requests for more work - and by the way, it is not uncommon for them to recommend rejection even after the demanded experiments are done if the results don't agree with the reviewers' preconceived notions of what they should look like. This crippling difficulty could be overcome if the professional editors of TBT were willing to make judgments that sometimes went against the recommendations of reviewers, but they almost never do that.

Another difficulty caused by the assumption that anything published in TBT must be of high impact is that simply counting the number of such papers has replaced actually reading publications in reviewing initial hiring and tenure candidates, not to mention postdoctoral fellowship applications. We are all so busy these days that it's tempting to use any seemingly valid proxy for the time-consuming work of assessing what a candidate actually contributed. Young scientists realize this, and thus clamor to have their work published in the TBT, even when it is much more appropriate for one of the excellent specialty journals, which results in needless disappointments, anxieties, and delays in getting work into print.

Yet another problem is that the imprimatur of TBT seems to sap the critical judgment of scientists, science journalists, and scientific administrators. They invest papers published therein with a cachet they don't always deserve. And this, in turn, makes it hard to publish later papers that contradict their findings, even though such papers are crucial to the way science moves forward.

Not all of these problems are the fault of TBT themselves; in fact, a number of them stem from laziness or ego on the part of the scientific community. But regardless of the cause, the situation has become dire. The culture of publication has become toxic, with editors who take too little responsibility and reviewers who take too much holding careers, especially of young scientists, hostage.

That is why we actually do need one more journal in this cornucopia we already have. A journal that can break the hegemony of TBT. A journal that can restore some sanity to what has become a crazy business. And the amazing thing is, we might actually be about to get one.

On June 27, 2011, the three leading non-governmental supporters of general biomedical sciences in the world (including genomics), the US's Howard Hughes Medical Institute, Germany's Max Planck Society, and Britain's Wellcome Trust announced that they would establish a new, top-tier, open access journal - not a completely general one, but one that would cover all areas of biomedical and life sciences research. The three organizations stated that they intended the new journal to attract, and thereby define, the very best research publications from across these fields.

Several important characteristics of the new, as yet unnamed journal would differentiate it immediately from TBT. First, it would be on-line only - no print edition. The intent of that is to increase the speed of publication and reduce the need for overly restrictive page limits that in turn necessitate supplemental data that few readers ever see. Second, the new journal would have all its editorial decisions made by actively practicing scientists, as is largely the case with the Proceedings of the National Academy of Sciences (PNAS). Third - and it's hard to overstate the importance of this - the journal would have the seemingly revolutionary but actually traditional policy of usually deciding on the merit of work in papers as actually submitted, rather than as some reviewer thinks it should be redesigned. To facilitate this process and ensure transparency, the reviewers' comments will be published, anonymously, along with the accepted manuscript.

That's right, as Sir Mark Walport, Director of the Wellcome Trust states, "This will be a journal for scientists, edited by scientists. The ethos of the journal will be to avoid asking authors to make extensive modifications or perform endless additional experiments before a paper can be published." Given the extremely deep pockets of its founders, the journal will be open access: the entire content will be freely available for all to read, to reproduce and for unrestricted use. For the first few years of its existence, there will be no page charges to publish there.

Robert Tjian, the President of the Howard Hughes Medical Institute, adds these comments: "We will define success by the influence the journal has within the scientific community - rather than by impact factor, the numerical score assigned to journals based on the number of times its articles are cited. I can offer one practical indicator that makes sense to me: Is this journal THE place where the best graduate students and postdocs want to publish their best work?... HHMI provided early support for the Public Library of Science, a pioneering open access publisher, and adopted policies to ensure rapid dissemination of research results. But institutional policies cannot, in and of themselves, address the frustrations of many practicing scientists as they navigate between the world of research and the world of publishing."

Tij (full disclosure: we shared an office as graduate students) goes on to state that, "I would like to focus on another aspect that exemplifies a significant goal of the new journal: redefining the size of the publishable unit. Just how many years of work should a single paper represent? This is a real and important question that confronts many labs, including my own. If a postdoc or graduate student spends six years on rigorously documenting a new discovery, should he or she then be 
required to conduct numerous additional experiments to satisfy reviewer comments? Where should the line be drawn? What is reasonable? I for one would like to see articles - that is, publishable units - reflect the fact that science itself is a continuum, that you can never have a complete story. You can, however, describe a compelling story of discovery that sets the stage for directing future inquiry and experimentation. That is what HHMI and its partners, the Wellcome Trust and Max Planck Society, seek to achieve in an efficient and timely manner without sacrificing originality, novelty, or rigor."

One possibly controversial decision is that reviewers as well as editors will be paid for their work for the new journal, though the magnitude and form of the compensation have yet to be announced. My own view is that, if there is a chance that economic incentives can speed up the process of manuscript peer review, it's a policy worth trying.

If all this sounds too good to be true, there is one more aspect of the new journal that gives even more hope it may actually succeed in its extremely ambitious goals. Randy Schekman, the outstanding biochemist/molecular biologist/yeast geneticist who has served as Executive Editor of PNAS since 2006, has been chosen to head it.
Randy (another disclosure: he is, like Tij, a friend of long standing) has, in my opinion, been an outstanding editor for $P N A S$, and brings both experience and prestige to this venture. He says his first priorities will be recruiting a managing executive editor to oversee the journal's business functions and identifying the scientific editors, including two deputies, 10 to 12 senior editors, and a larger board of reviewing editors. He also says that the journal will not favor papers submitted by investigators supported by the three societies that fund it, and if Randy says that, you can take it to the bank.

The only bad thing I can see about this new journal is that the first issue is not scheduled to be published until the summer of 2012. Which means, I guess, that Christmas will be a little late this year.

Published: 29 September 2011

doi:10.1186/gb-2011-12-9-129

Cite this article as: Petsko GA: The one new journal we might actually need. Genome Biology 2011, 12:129. 